\title{
Handoff Management protocols MIPV6 and HMIPV6 Comparative analysis in 4G wireless networks
}

\author{
Sonali Chavan ${ }^{1}$, Vanita Mane ${ }^{2}$ \\ Computer Department, RAIT, Nerul, Navi Mumbai, India
}

\begin{abstract}
With the increasing demands for new data and real-time services, wireless networks should support calls with different traffic characteristics and different Quality of Service $(Q o S)$ guarantees. Instead of developing a new uniform standard for all wireless communications systems, $4 G$ communication networks strive to seamlessly integrate various existing wireless communication technologies. IP has been recognized to be the de facto protocol for next-generation integrated wireless. In this paper we discuss different types of protocol for handoff management in 4G. Mobile IPv6, Hierarchical Mobile IPv6 and their comparative study and analysis. Keywords: $4 G$ networks, Handoff management, Handoff latency, HMIPV6, MIPV6
\end{abstract}

Accepted Date: 14 June 2013

\section{INTRODUCTION}

4G networks are designed to be heterogeneous networks, which allow users having integrated devices to access connectivity anywhere and everywhere. The expectation for the 4G technology is basically the high quality audio/video streaming over end to end Internet Protocol. Currently, most of research work on handoff issues in 4G systems focuses on keeping unbroken communications with timely location update or reducing handoff latency and packet loss in IP-based wireless networks. fast and seamless handover is a big challenge for 4G heterogeneous networks that are supposed to support real-time high speed multimedia applications that require small handoff delay and high data-rate transmission.

Handoff Management: Handoff management is the process by which a mobile node keeps its connection active when it moves from one access point to another.. Depending on the movement of the mobile device, it may undergo various types of handoff. In a broad sense, handoffs may be of two types: (i) intrasystem handoff (horizontal handoff) and (ii) inter-system handoff (vertical handoff). Handoffs in homogeneous networks are referred to as intra-system handoffs. This type of handoff occurs when the signal strength of the serving BS goes below a certain threshold value. Inter-System Handoff between two BSs, belong to two different systems.

Horizontal handoff: The mobile node moves between two access points (which is adjacent to each other) of same network. The reason for such handoff could be poor signal strength, local interference, load balancing.

Vertical handoff: The mobile node moves between two access points of different network The reason for such handoff could be poor signal strength, local interference.

There are three stages in a handoff process. First, the initiation of handoff is triggered by the mobile device, or a network agent, other changing network conditions. The second stage is for a new connection generation, where the network must find new resources for the handoff connection and perform any additional routing operations. Finally, data-flow control needs to maintain the delivery of the data from the old connection path to the new connection path according to the agreed upon QoS guarantees

Network discovery: A mobile terminal (MT) searches for reachable wireless networks during the network discovery process. A multimode (equipped with multiple access network interfaces) MT must activate the interfaces to receive service advertisements broadcasted by different wireless technologies. A wireless network is reachable if its service advertisements can be heard by the MT. The simplest way to discover reachable wireless networks is to always keep all interfaces on.

Handoff Decision: It refers to the process of deciding to which access network to connect at any point of time. This allows the best access network to be selected and handover to this access network to be initiated. In fact, based on the gathered information, the available interfaces, the user preferences and the black list, mobile terminal evaluates the neighbouring access networks and select the most suitable one. 
Handoff Execution: The main goal of handover execution is to preserve session continuity while changing the point of attachment. Handover follows access network selection. After a new link is setup, all the communications associated with the old link are transferred to the new link. The control signals and data packets are allocated to the connection associated with the new base station or access point. Once the selected access network differs from the serving one, the handover execution is performed. If the handover fails, the network selection will attempt to select another access network.

\section{LITERATURE SURVAY}

Ibrahim Al-Surmi,et al. [1] had classified and evaluated the existing mobility protocols based on their managed layer, mobility base (i.e., host-based and network-based) along with different aspects of their protocols. This article had also identified the features of each of the mobility management protocols in respect of other protocols, which provide a comprehensive view of the mobility protocols current state with their efficiencies, capabilities, and drawbacks to support mobility management.

C. Makaya and S. Pierre [2] have proposed a comprehensive analytical model for IPv6-based mobility protocols (i.e., MIPv6, HMIPv6, FMIPv6 and F-HMIPv6) in order to provide depth analysis of the overall performance of these protocols. These protocols have been compared and evaluated in terms of signaling cost, binding refresh cost, packet delivery cost, required buffer space, and handover latency. In the paper, the authors presented the effect of subnet residence time, packet arrival rate, and wireless link delay to the different IPv6 mobility management protocols.

Xavier Pérez Costa, Ralf Schmitz, Hannes Hartenstein, Marco Liebsch [3]performed study to assess the most appropriate approach for the functional specification and the implementation, specially with respect to the implementation for the project's field trial by comparing MIPv6, FMIPv6 and HMIPv6 for handover latency. The author concluded that when MIPv6 is compared with HMIPv6 or FMIPv6, HMIPv6 and FMIPv6 assures an equal or better performance, referring to handover latency, than basic MIPv6 for most of the cases.

\section{Mobile IPv6 Protocol[4]}

\section{HANDOFF PRotocols Schemes}

Mobile IPv6 is mainly proposed to keep any communication between a mobile node and a correspondent node $(\mathrm{CN})$ while the mobile node moves from one IPv6-based sub-network to another one. In this design, each MN has a home address identifying its home network. Within its home network, each MN uses the traditional routing functions to exchange IP datagram with its $\mathrm{CN}$. Whenever an $\mathrm{MN}$ moves from its local network to a new network, its home address becomes invalid. And then the MN can create a new address called care-of address (CoA) from a router advertisement message sent by the new visited network. A binding between MN's CoA and its home address is updated to the MN's home agent to keep continuous communications between the $\mathrm{MN}$ and its correspondent(s). In this way, MN's home agent can always detect coming communication packets to MN with MN's home address, and locate the current position of MN with MN's $\mathrm{CoA}$. At the beginning of the handover procedure, an MN can use"Neighbour Discovery" scheme, which is based on reception of Router Advertisement (RA) sent by current access router (AR), to detect its movement to a new subnet, as shown in Figure 1 (arrow line 1). After verifying the uniqueness of its link local address on the new link, the MN will create an IPv6 address called CoA from the corresponding prefix in RA. After that, MN will exchange binding update information which include MN's CoA with its HA and its CN to allow all of them to maintain their connections, shown in Figure (arrow line 2).Mobile IPv6 can reasonably keep track of MN's new address by timely binding update between the $\mathrm{MN}$ and its home gent. However, before finishing binding update, data packet communications are interrupted. The MN needs to spend time discovering new subnet, establishing new care-of address, and exchanging information between $\mathrm{MN}$ and its home agent. For 4G highspeed data multimedia communications, all of them will create a lot of signalling traffic and latency, resulting in packet loss. It is even worse when an MN roams between two ARs several times. This frequent roaming will cause ping pong effects, which refer to the situation in which too frequent and unnecessary location updates and handoffs occur in a short time. In this case, MN cannot keep normal continuous communications with its $\mathrm{CN}(\mathrm{s})$. In the mean time, all packets destined for the old care-of address are dropped. Therefore, we need to improve binding update procedure of Mobile IPv6 handover schemes to reduce handoff latency and signalling traffic. [4] 


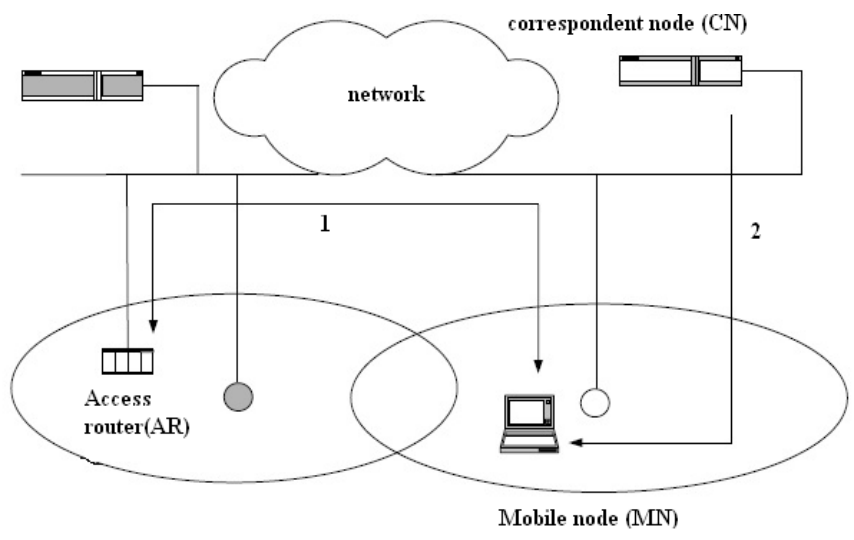

Fig1. Mobile IPv6 wireless network

\section{Hierarchical Mobile IPv6[4]}

Hierarchical Mobile IPv6 (HMIPv6) is developed to reduce the amount of signalling traffic required, which affects handoff latency of MN's communications. Unlike MIPv6, HMIPv6 addresses the issue of local mobility and global mobility separately, which means local handoffs are managed locally without notifying home agent, while global mobility is managed with the MIPv6 protocol. In HMIPv6, the global internet is divided into regions for local area mobility and each region is connected to the rest of IP network with a new node called Mobility Anchor Point (MAP), which is a kind of anchor point in charge of several ARs as shown in Figure In this scheme, each mobile node has two care-of addresses. One is a regional care-of address and the other is a local care-of address.

The regional care-of address is local to the MAP's covered region. An MN communicates with its correspondent nodes via its regional care-of address. When an $\mathrm{MN}$ moves into a new region or domain, it will first get a regional care-of address from MAP advertisement information, and then the MN will inform its home agent and its correspondents about its "regional location" as its raw location information. When the MN moves between two ARs in the same region covered by a same MAP, MN will update its localization into the domain and get a new local care of address by sending local registration to the MAP, instead of sending to its home agent. The MAP intercepts data packets designated to MN's regional care-of address and tunnels them to the corresponding MN's local care-of address. So in this way, handoff latency and signalling traffic are reduced because each $\mathrm{MN}$ hides its local movements in a region from its home agent and correspondents, and meanwhile MN can keep unbroken communications with its correspondent(s). [4]

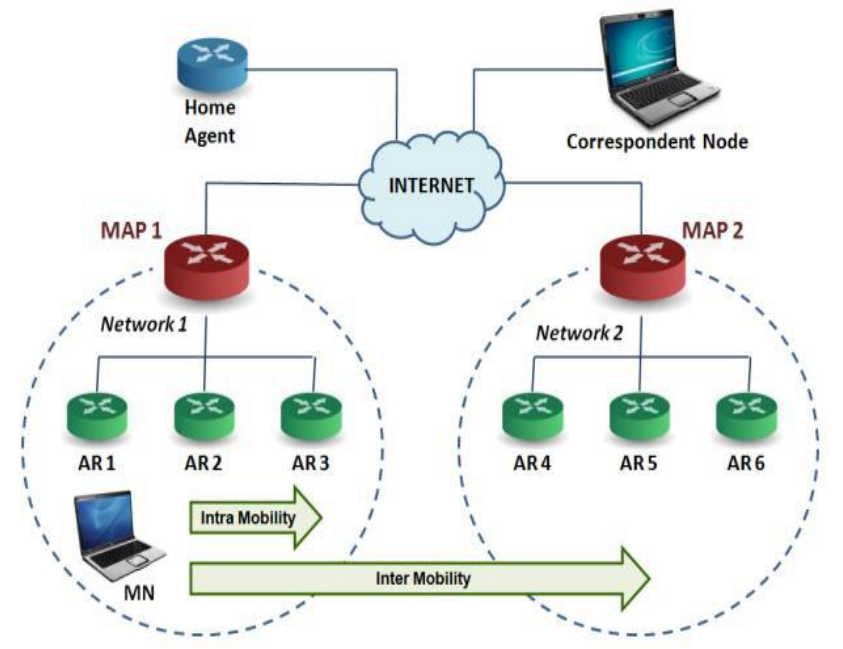

Fig2. Hierarchical Mobile IPv6 Architecture 


\section{DISCUSSION AND ANALYSIS \\ TABLE I}

COMPARATIVE STUDY AND ANALYSIS HANDOFF SCHEMES BASED FOR IP BASED NEXT GENERATION (4G)

\begin{tabular}{|l|l|l|}
\hline Parameters & $\begin{array}{l}\text { MOBILE IPV6 } \\
\text { SCHEME }\end{array}$ & $\begin{array}{l}\text { HIRARCHICAL } \\
\text { MOBILE } \\
\text { SCHEME }\end{array}$ \\
\hline Mobility management type & Host Based & Host Based \\
\hline Return routability & Required & Not required \\
\hline $\begin{array}{l}\text { Topologically } \\
\text { correspondent entity }\end{array}$ & AR & AR/MAP \\
\hline Signaling traffic & Increase & Decrease \\
\hline Handoff & Inter domain & Intra\& inter domain \\
\hline Improvement & Binding update procedure & $\begin{array}{l}\text { Dynamic load distribution } \\
\text { \& selection among MAP's }\end{array}$ \\
\hline Protocol & MIPV6 & HMIPV6 \\
\hline
\end{tabular}

\section{Handover latency analysis}

The handoff latency at an MN side is defined as the time interval during which an MN cannot send or receive any packets during handoff and it is composed of L2 (link layer) and L3 (IP layer) handoff latencies [5].

The L3 handoff latency is the sum of delay due to movement detection, IP addresses configuration and binding update procedure.

Following notations are considered for analysis from [6] [7].

\begin{tabular}{ll}
\hline \hline L & Length of Handoff Latency \\
$\mathrm{D}$ & Total signaling cost for handoff \\
$\mathrm{T}(\mathrm{L} 2)$ & Layer 2 handoff latency/cost \\
$\mathrm{T}(\mathrm{MD})$ & Movement Detection latency/cost \\
$\mathrm{T}(\mathrm{DAD})$ & Duplicate Address Detection latency/cost \\
$\mathrm{T}(\mathrm{BU})$ & Binding Update latency/cost for HA/CN \\
$\mathrm{T}(\mathrm{BU}-\mathrm{MAP})$ & Binding Update latency/cost for MAP/NMAP \\
$\mathrm{m}$ & Latency or cost of packet delivery between MN and Access Router \\
& (PAR/NAR/MAP/MAG/LMA/AN) \\
$\mathrm{a}$ & Latency or cost of packet delivery between MN and HA \\
$\mathrm{b}$ & Latency or cost of packet delivery between HA and CN \\
$\mathrm{c}$ & Latency or cost of packet delivery between MN and CN \\
\hline \hline
\end{tabular}

Let L(MIPv6) be handoff latency of MIPv6. Then it can be expressed as:

$$
\begin{aligned}
& \mathrm{L}(\mathrm{MIPv} 6)=\mathrm{T}(\mathrm{L} 2)+\mathrm{T}(\mathrm{MD})+\mathrm{T}(\mathrm{DAD})+\mathrm{T}(\mathrm{BU}) \\
& \mathrm{L}(\mathrm{MIPv} 6)=\mathrm{T}(\mathrm{L} 2)+2 \mathrm{~m}+2 \mathrm{~m}+(4 \mathrm{a}+2 \mathrm{~b}+4 \mathrm{c})
\end{aligned}
$$

Where $\mathrm{T}(\mathrm{L} 2)$ is link layer latency, $\mathrm{T}(\mathrm{MD})$ is movement detection latency, $\mathrm{T}(\mathrm{DAD})$ is duplicate address detection latency, and $\mathrm{T}(\mathrm{BU})$ is binding update and return rout ability latency.

Let L(HMIPv6-Intra) be handoff latency of HMIPv6 Intra-MAP Domain handoff. Then it can be expressed as:

$\mathrm{L}($ HMIPv6-Intra domain $)=\mathrm{T}(\mathrm{L} 2)+\mathrm{T}(\mathrm{MD})+\mathrm{T}(\mathrm{DAD})+\mathrm{T}(\mathrm{BU}-\mathrm{MAP})$

L(HMIPv6-Intradomain $)=T(L 2)+2 m+2 m+2 m$

Where $\mathrm{T}(\mathrm{L} 2)$ is link layer latency, $\mathrm{T}(\mathrm{MD})$ latency for movement detection, $\mathrm{T}(\mathrm{DAD})$ for duplicate address detection and T(BU-MAP) is latency for binding update between MN and MAP which is less than T(BU) of MIPv6 (i.e T(BU-MAP) < T(BU) ). As MN moves within same MAP domain, binding update and return routability between $\mathrm{MN}$ and $\mathrm{HA} / \mathrm{CN}$ is not required to be performed.

Let L(HMIPv6-Inter) be handoff latency of HMIPv6 Inter-MAP Domain handoff. Then it can be expressed as:

$\mathrm{L}($ HMIPv6- Inter domain $)=\mathrm{T}(\mathrm{L} 2)+\mathrm{T}(\mathrm{MD})+\mathrm{T}(\mathrm{DAD})+\mathrm{T}(\mathrm{BU}-\mathrm{NMAP})+\mathrm{T}(\mathrm{BU})$

$\mathrm{L}($ HMIPv6-Inter domain $)=\mathrm{T}(\mathrm{L} 2)+2 \mathrm{~m}+2 \mathrm{~m}+2 \mathrm{~m}+(4 \mathrm{a}+2 \mathrm{~b}+4 \mathrm{c})$

Where, $\mathrm{T}(\mathrm{L} 2)$ is link layer latency, $\mathrm{T}(\mathrm{MD})$ latency for movement detection, $\mathrm{T}(\mathrm{DAD})$ for duplicate address detection and T(BU-NMAP) is latency for binding update between MN and NMAP. In this case, MN needs to update HA/CN about MN's new RCoA on new MAP. Hence T(BU) is also added. 
Table 2: handoff latency analysis of MIPV6 and HMIPV6

\begin{tabular}{|c|c|c|}
\hline \multirow{2}{*}{\multicolumn{2}{|c|}{$\begin{array}{l}\text { Handoff Protocols } \\
\text { In 4G wireless networks } \\
\text { MIPv6 }\end{array}$}} & Handoff Latency \\
\hline & & $\mathrm{T}(\mathrm{L} 2)+(2 \mathrm{~m})+(2 \mathrm{~m})+(4 \mathrm{a}+2 \mathrm{~b}+4 \mathrm{c})$ \\
\hline \multirow{2}{*}{ HMIPv6 } & $\begin{array}{l}\text { Intra } \\
\text { Domain }\end{array}$ & $\mathrm{T}(\mathrm{L} 2)+(2 \mathrm{~m})+(2 \mathrm{~m})+(2 \mathrm{~m})$ \\
\hline & $\begin{array}{l}\text { Inter } \\
\text { Domain }\end{array}$ & $\mathrm{T}(\mathrm{L} 2)+(2 \mathrm{~m})+(2 \mathrm{~m})+(2 \mathrm{~m})+(4 \mathrm{a}+2 \mathrm{~b}+4 \mathrm{c})$ \\
\hline
\end{tabular}

\section{CONCLUSION}

In this paper we give an overview of handoff management in $4 \mathrm{G}$ technology, and comparison current handoff techniques for IP-based 4G mobile networks. Specifically, we have described and analyses handoff protocol schemes in details, Mobile IPv6, Hierarchical Mobile IPv6. Mobile IPv6 protocols define a care-of address for MN in a new visited network.. Among we analyze handoff latency of MIPv6 and HMIPV6 protocol schemes.Future work should be carried out in determining other new obstacles in handoff schemes and protocols need to be improved.

\section{REFERENCES}

[1] Ibrahim Al-Surmi, Mohamed Othman, Borhanuddin Mohd Ali, "Mobility management for IP-based next generation mobile networks: Review, challenge and perspective", ELSEVIER Journal of Network and Computer Applications 35, 2012.

[2] C. Makaya and S. Pierre, "An Analytical Framework for Performance Evaluation of IPv6-Based mobility Management Protocols", IEEE Transactions on Wireless Communications, vol. 7, no. 3, pp. 972-983, March 2008.

[3] Xavier Pérez Costa, Ralf Schmitz, Hannes Hartenstein, Marco Liebsch, “A MIPv6, FMIPv6 and HMIPv6 handover latency study: analytical approach"

[4] P Deepika H1, Nilakshee R2 and Bhavana A3," Handover in next generation networks - challenges and solution", World Journal of Science and Technology 2012, 2(4):89-92ISSN: $2231-2587$.

[5] C. Makaya and S. Pierre, "An Analytical Framework for Performance Evaluation of IPv6-Based mobility Management Protocols", IEEE Transactions on Wireless Communications, vol. 7, no. 3, pp. 972-983, March 2008.

[6] Jong-Hyouk Lee, Jean-Marie Bonnin, Ilsun You, Tai-Myoung Chung, "Comparative Handover Performance Analysis of IPv6 Mobility Management Protocols”, IEEE Transactions On Industrial Electronics, 2012.

[7] Nguyen Van Hanh, Soonghwan Ro, Jungkwan Ryu, "Simplified fast handover in mobile IPv6 networks", ELSEVIER Computer Communications 31,2008.

[8] Xavier P’erez-Costaa Marc Torrent-Moreno, “A Performance Comparison of Mobile IPv6, Hierarchical Mobile IPv6, Fast Handovers for Mobile IPv6 and their Combination”. Mobile Computing and Communications Review, Volume 7, Number 4.

[9] Archan Misra, Subir Das, "IDMP-based FAST HANDOFFS AND PAGING INIP-BASED CELLULAR NETWORKS" 2001 Telcordia Technologies Inc. and the University of Texas at

[10] Arlington ROSLI SALLEH and XICHUN LI "HANDOFF TECHNIQUES FOR 4G MOBILE WIRELESS INTERNET “3rd International Conference: Sciences of Electronic, Technologies of Information and Telecommunications March 27-31, 2005 TUNISIA

[11] Sarddar D,Joydeep Banerjee, “A Handoff Management for Next Generation Wireless Systems

[12] Gaurang N1 ,Vignesh A2 ,Pulkit S3, et al. "Challenges in the implementation of Fourth Generation Wireless Systems" Vol. 2, Issue 2,Mar-Apr 2012, pp.1353-1355

[13] Wafaa A. H. Ali Al Salihy, “A Survey in Mobile Generations and their Mobility Management” ISSN 1450-216X Vol.58 No.1 (2011), pp.88-102 